Article

\title{
Effect of Temperature on the Composition of a Synthetic Hydrocarbon Aviation Lubricating Oil
}

\author{
Zhuoting Gan ${ }^{1}$, Ting Yao ${ }^{2, *}$, Meng Zhang ${ }^{2}$, Jianqiang $\mathrm{Hu}^{3}$, Xiaoxiao Liao ${ }^{4}$ and Yongli Shen ${ }^{4}$ \\ School of Tourism, Huangshan University, Huangshan 245041, China; ganzhuoting@hsu.edu.cn \\ Analysis and Test Center, Huangshan University, Huangshan 245041, China; zm539286@163.com \\ Department of Aviation Oil, Air Force Logistics College, Xuzhou 221006, China; hjq555918@sohu.com \\ 4 Unit 94923 of People's Liberation Army of China, Wuyishan 354301, China; wyslxx516@163.com (X.L.); \\ shen372321@163.com (Y.S.) \\ * Correspondence: yting@hsu.edu.cn
}

Received: 29 February 2020; Accepted: 27 March 2020; Published: 1 April 2020

check for updates

\begin{abstract}
Synthetic hydrocarbon aviation lubricating oils (SHALOs) gradually degrade over time when subjected to high temperatures, resulting in their composition and properties varying over the operation lifetime. Therefore, understanding the SHALO degradation properties by elucidating the mechanism on a molecular level, as a function of high temperature, is of interest. A SHALO was subjected to thermal treatment (TT) at $180,200,230,250,270$, or $300^{\circ} \mathrm{C}$ for $2 \mathrm{~h}$. The chemical compositions of six TT samples and one fresh oil were analyzed by fourier transform infrared $\mathrm{F}$ spectroscopy, advanced polymer chromatography, and gas chromatography/mass spectrometry. Furthermore, the physicochemical properties, such as kinematic viscosity, pour point, and acid number, of seven samples were determined. The oil samples were grouped by cluster analysis (CA) using a statistical method. The SHALO was identified to comprise 20 functional groups, including comb-like alkanes, long-chain diesters, amines, phenols, and other compounds. TT at $<230{ }^{\circ} \mathrm{C}$ caused partial cracking of the SHALO base oils, with a concomitant change in the antioxidant content and type, and the polycondensation reactions were dominant. The observed antioxidant changes were not obvious from TT at $>230^{\circ} \mathrm{C}$. A large number of small-molecule compounds were detected, including n-alkanes and olefins. TT at $250^{\circ} \mathrm{C}$ was shown to be an important threshold for the kinematic viscosity, pour point, and acid number of the samples. Below $250^{\circ} \mathrm{C}$, the sample properties were relatively stable; but at elevated TT temperatures $\left(>250{ }^{\circ} \mathrm{C}\right)$, the properties were observed to dramatically degrade. As the sample color was highly sensitive to temperature, the TT temperature induced rapid and significant color changes. The CA analysis results for the oil compounds at the molecular level were in good agreement with observed changes in the physicochemical properties at the macro level.
\end{abstract}

Keywords: synthetic hydrocarbon aviation lubricating oil; high temperature; composition; structure; advanced polymer chromatography; cluster analysis

\section{Introduction}

Synthetic lubricating oils (SLOs) are liquid lubricants, possessing specific structures and properties derived from organic synthesis. Compared with vegetable oils and mineral-based lubricating oils, SLOs have the advantages of eco-compatibility, excellent thermal stability, and low-temperature behavior [1,2]. There are six types of SLOs, namely, synthetic hydrocarbon oils, organic acid ester synthetic oils, polyether synthetic oils, phosphate esters, fluorine-containing oils, and silicone oils. The SLO types exhibit significant differences in chemical structure, lubricating properties, and antidegradation behaviors compared with the base oil. Therefore, specific SLOs are better suited to different working 
conditions. Hydrocarbon and ester synthetic oils are often employed in the military, aerospace industry, and under other harsh working conditions owing to their anti-high temperature performance [3].

The base oil is the principal component of an SLO, accounting for 70-90 wt.\%, and is not only the carrier of lubricating additives but also directly determines the lubricating performance [4]. The base oil of synthetic hydrocarbon aviation lubricating oil (SHALO) is synthesized from ethylene as the raw material, which is first polymerized into an $\alpha$-olefin, followed by polymerization to afford a poly- $\alpha$-olefin (PAO), or obtained by copolymerization of PAO with ethylene. PAO has a unique comb-like hydrocarbon structure that enables SHALO to possess excellent viscosity-temperature properties, low-temperature fluidity, low volatilization loss, and good thermal and hydrolysis stability. Furthermore, the PAO properties enable SHALO to exhibit excellent oxidation, shear, and low corrosion properties, as well as excellent lubrication and wear properties $[5,6]$.

With the development of aero-engines designed to improve thrust-to-weight ratios while maintaining high reliability and durability, the operating conditions that lubricants are subjected to are becoming increasingly complicated and demanding [7]. When in use, the temperature near to the first piston ring of the main bearing can reach $200-300{ }^{\circ} \mathrm{C}$ [8]. High temperatures are considered a critical factor in the acceleration of lubricant degradation, which might impact flight safety under harsh conditions $[9,10]$. Recently, much interdependent research has focused on the effect of temperature on the degradation of synthetic aviation lubricants, with respect to lubricating properties and the associated mechanisms [11-13].

Research has shown that high temperatures accelerate the cracking, oxidation, and polymerization reactions of SHALO $[14,15]$ while also promoting the desorption of lubricants that negatively impact directional adsorption, melting the oil film [16], and reducing the anti-foaming performance [17]. Furthermore, carbide accumulation [18-20], the blockage of fuel supply lines and filtration systems [21], and reduced thermal conductivity of the engine are often observed during oxidation at high temperatures. Therefore, tight and stagnant moving joints [22,23] form, resulting in reduced engine operation and service life. Although some reports have demonstrated that high temperatures reduce the lubricating properties of SHALO, other studies have observed improved friction properties after the appearance of oxidized derivatives in aged oils [24]. Therefore, elucidating the SHALO lubricating properties as a function of engine warming during aircraft flight is required.

The present study also aimed to demonstrate how changes in the SHALO molecular structure and base oil composition through organic synthesis design improve the lubricating properties of lubricating oils and increase compound stability. Changes to the compound structures and SHALO compositions are the principal reason for the degradation of lubricating properties. Furthermore, changes in the molecular structure and composition as a function of the heating process need to be elucidated at the molecular level.

The gas-phase thermal degradation of three commercial industrial lubricants (two different triaryl phosphate compositions and one based on fatty acid methyl and ethyl esters) was investigated under oxidative pyrolysis conditions between 400 and $1000^{\circ} \mathrm{C}$ by Mascolo et al. [25]. Significant differences were observed in the thermal stability between lubricants containing phosphorus and those without phosphorus. Lubricant degradation in the absence of phosphorus was assumed to start with the breakdown of aliphatic moieties to generate vinyl radicals, which, in turn, afforded benzene radicals and polycyclic aromatic hydrocarbons (PAHs) through displacement and cyclization reactions. However, phosphorus-based lubricants degraded to directly form benzene radicals and PAH structures through consecutive reactions. At temperatures of $>700{ }^{\circ} \mathrm{C}$, the benzene and PAH contents in the degradation products of lubricants without phosphorus were significantly lower than in corresponding lubricants containing phosphorus [25]. Various types of synthetic lubricants are observed to undergo different degradation processes.

Tripathi and Vinu [26] observed that the major hydrocarbon present in fresh synthetic oil was tetratriacontane $\left(\mathrm{C}_{34} \mathrm{H}_{70}\right)$ and that the oxidative degradation of synthetic oil as a function of temperature resulted in the formation of shorter-chain hydrocarbons as the major products. For example, shorter-chain hydrocarbons, such as pentadecane $\left(\mathrm{C}_{15} \mathrm{H}_{32}\right)$ and hexadecane $\left(\mathrm{C}_{16} \mathrm{H}_{34}\right)$, were the major 
products at $200{ }^{\circ} \mathrm{C}$, while longer-chain hydrocarbons, such as tetrapentacontane $\left(\mathrm{C}_{54} \mathrm{H}_{110}\right)$ and hexacontane $\left(\mathrm{C}_{60} \mathrm{H}_{122}\right)$, were observed along with other hydrocarbons at 120 and $149^{\circ} \mathrm{C}$, respectively. The chemical reactions of synthetic lubricants during heating are complicated, with cracking and polymerization phenomena occurring simultaneously. The oxidation mechanism of SHALOs is generally considered to occur via a radical chain mechanism, in which the hydrocarbons in the lubricating oil are pyrolyzed to form organic free radicals that react with oxygen to form peroxy radicals and peroxides, and thereafter, polymerize to form oligomers [21,27,28]. However, Wu et al. [15] subjected synthetic lubricating oil diethylhexyl sebacate (DEHS) to continuous high-temperature treatment $\left(150^{\circ} \mathrm{C}\right)$ and observed that DEHS degradation not only resulted in oxidation reactions but also hydrolysis reactions. Furthermore, Santos et al. [29] observed that the content of insoluble high-molecular-weight polymers in mineral lubricating oils increased as a function of temperature, together with an increase in the kinematic viscosity (KV) of the lubricating oils. Meanwhile, computational methods are valuable tools for determining properties that are dependent on the microstructure. Gueorguiev et al. developed the synthetic growth concept based on density functional theory, with their computational experiment providing useful information to achieve a systematic understanding of the stability/reactivity and identification of the various compounds [30,31]. Furthermore, the thermal oxidation process of lubricating oils has been simulated using visual reactive force field molecular dynamics at an atomic level $[9,13]$. Typically, the degradation process of lubricating oils at high temperatures is relatively complicated from a molecular perspective. The influence of temperature on the structure and composition of lubricating oils still requires elucidation, while structural and compositional changes during the heat treatment of lubricating oils, especially SHALOs, remain unclear.

Based on actual working conditions, SHALO was subjected to thermal treatment (TT) at six different temperatures. The six TT samples and one fresh oil were analyzed by fourier transform infrared spectroscopy (FT-IR), advanced polymer chromatography (APC), and gas chromatography/mass spectrometry (GC/MS) to explore changes in the SHALO composition and structure in more detail. Furthermore, the degradation mechanism and physicochemical properties were described, including $\mathrm{KV}$, pour point (PP), acid number (AN), and color. This study aimed to develop an understanding of the SHALO macroscopic-microscopic structure relationship and to elucidate changes in the composition and physicochemical properties as a function of the TT process.

\section{Experimental}

\subsection{Materials}

The SHALO sample was supplied by Unit 94923 of the People's Liberation Army of China. SHALO comprised base oils, which are low-viscosity PAOs, together with nominal amounts of esters (ETs) and additives, such as antioxidants, antifoaming agents, and preservatives. The SHALO KV at $100{ }^{\circ} \mathrm{C}$ was $\geq 3 \mathrm{~mm}^{2} / \mathrm{s}$, the $\mathrm{AN}$ was $\leq 0.05 \mathrm{mg} \mathrm{KOH} / \mathrm{g}$, and the specified operating temperature range was -40 to $200{ }^{\circ} \mathrm{C}$. All solvents used in experiments were commercially purchased analytical reagents and purified by distillation prior to use.

\subsection{Sample Preparation}

SHALO (150 mL) was placed into a 500-mL stainless-steel autoclave and heated to 180, 200, 230, 250, 270, or $300^{\circ} \mathrm{C}$ with magnetic stirring at $1000 \mathrm{rpm}$, and each temperature was maintained for 2 $\mathrm{h}$, followed by immediately cooling of the reactor to room temperature in an ice-water bath within $0.5 \mathrm{~h}$. The TT samples were obtained from the autoclave by filtration through a polytetrafluoroethylene membrane (pore size, $0.45 \mu \mathrm{m}$ ) and denoted as $S_{180}, S_{200}, S_{230}, S_{250}, S_{270}$, and $S_{300}$, respectively. The untreated oil control sample was denoted as $S_{\mathrm{rt}}$. 


\subsection{Sample Analysis}

All SHALO samples were characterized by FT-IR spectroscopy and APC. FT-IR spectra were recorded using an FT-IR spectrometer (Nicolet 380, Thermo Fisher, Waltham, MA, USA) across a wavenumber range of $400-4000 \mathrm{~cm}^{-1}$. Each sample was mixed with $\mathrm{KBr}$ and pressed into a pellet for FT-IR analysis. APC analysis was performed using a GC system (ACQUITY APC, Waters, Milford, MA, USA) equipped with three ACQUITY APC XT columns placed in series, as follows: $450 \AA$ column $(4.6 \times 150 \mathrm{~mm}, 2.5 \mu \mathrm{m}) ; 200 \AA$ column $(4.6 \times 150 \mathrm{~mm}, 2.5 \mu \mathrm{m}) ; 45 \AA$ column $(4.6 \times 150 \mathrm{~mm}$, $1.7 \mu \mathrm{m})$. The ranges of effective molecular weights of each column were $20,000-400,000,3000-70,000$, and 200-5000, respectively. The columns were kept at $45{ }^{\circ} \mathrm{C}$. Tetrahydrofuran (THF) was used as the mobile phase at a flow rate of $0.5 \mathrm{~mL} / \mathrm{min}$. Each sample $(5 \mathrm{mg})$ was diluted to $1.5 \mathrm{~mL}$ with THF. The injection volume was $10 \mu \mathrm{L}$.

All samples were analyzed by GC/MS using a GC/MS system (Hewlett-Packard 6890/5973, Agilent, Santa Clara, CA, USA) equipped with a capillary column coated with HP-5MS (30 m $\times 0.25 \mathrm{~m}$ inner diameter, film thickness of $0.25 \mu \mathrm{m}$, cross-linked $0.5 \%$ PhMe siloxane). The injector temperature was set at $300{ }^{\circ} \mathrm{C}$, with high purity helium used as the carrier gas. The electron impact mode ion source temperature was set at $230{ }^{\circ} \mathrm{C}$, with the electron energy set at $70 \mathrm{eV}$, and a mass range of $\mathrm{m} / \mathrm{z} 35-500$. The initial oven temperature was $120^{\circ} \mathrm{C}$, which was increased to $274{ }^{\circ} \mathrm{C}$ at a rate $13^{\circ} \mathrm{C} \mathrm{min}{ }^{-1}$, then to $281^{\circ} \mathrm{C}$ at a rate of $0.5^{\circ} \mathrm{C} \mathrm{min}-1$, holding for $2 \mathrm{~min}$, and finally to $300^{\circ} \mathrm{C}$ at a rate of $12{ }^{\circ} \mathrm{C} \mathrm{min}-1$, holding for $5 \mathrm{~min}$. Data acquired was processed using MSD ChemStation software (D.02.00, Agilent, Santa Clara, CA, USA). Compounds were identified by comparing the mass spectra with NIST11 library data. The relative content of each compound was determined by peak area normalization. Compounds were analyzed using Origin Pro 2018 software (OriginLab, Northampton, MA, USA) for cluster analysis (CA).

The physicochemical properties were determined simultaneously. The color was determined using a visual method (GB/T6540-1986) [32], KV was measured using a glass capillary viscometer (GB/T 265/1988) [33] at $40{ }^{\circ} \mathrm{C}$, AN was determined using a glass indicator electrode method (GB/T7304-2000) [34], and PP was determined using a PP method (GB/T3535-2006) [35].

\section{Results}

\subsection{Subsection FT-IR Analysis}

As shown in Figure 1, there were no significant differences between the $S_{180}-S_{300}$ and $S_{\text {rt }}$ FT-IR spectra. Twenty functional groups were detected in the FT-IR spectra (Table 1). Some functional groups exhibited absorbances attributed to aliphatic moieties at $\sim 2854, \sim 2925$, and $2957 \mathrm{~cm}^{-1}, \mathrm{C}=\mathrm{O}$ vibrations at $\sim 1741 \mathrm{~cm}^{-1}, \mathrm{CH}_{2}$ vibrations at $\sim 1465 \mathrm{~cm}^{-1},-\mathrm{CH}\left(\mathrm{CH}_{3}\right)_{2}$ vibrations at $\sim 1378 \mathrm{~cm}^{-1},=\mathrm{CH}-\mathrm{H}$ vibrations at $\sim 970 \mathrm{~cm}^{-1}$, and $-\left(\mathrm{CH}_{2}\right)_{\mathrm{n}}$ - vibrations at $\sim 720 \mathrm{~cm}^{-1}$, which were significantly stronger than others, implying that the components in the oil samples mainly comprised these groups.

The bands at 2957, 2925, and $2854 \mathrm{~cm}^{-1}$ were attributed to aliphatic $-\mathrm{CH}_{3}$ and $-\mathrm{CH}_{2}$ stretching vibrations, the band at $\sim 1465 \mathrm{~cm}^{-1}$ was attributed to $-\mathrm{CH}_{2}$ shear bending vibrations, and the band at $1378 \mathrm{~cm}^{-1}$ was assigned to the $\mathrm{C}-\mathrm{H}$ deformation vibration in $-\mathrm{CH}\left(\mathrm{CH}_{3}\right)_{2}$. A sharp and strong band was observed at $721 \mathrm{~cm}^{-1}$, implying that samples were rich in four or more $-\mathrm{CH}_{2}$ moieties. Functional groups detected in the samples indicated an abundance of long-chain aliphatic species.

The peak at $1741 \mathrm{~cm}^{-1}$ was assigned to the $\mathrm{C}=\mathrm{O}$ stretching vibration in saturated fatty acid esters $\left(v_{\mathrm{C}=\mathrm{O}}\right)$. The peaks at 1169 and $1142 \mathrm{~cm}^{-1}$ were attributed to the $\mathrm{C}-\mathrm{O}-\mathrm{C}$ stretching vibrations in long-chain fatty acid esters $\left(v^{\text {as }}(\mathrm{COC})\right)$, suggesting an abundance of long-chain fatty acid esters present in the sample.

The weak peaks located at $\sim 2730$ and $\sim 2672 \mathrm{~cm}^{-1}$ were assigned to the $-\mathrm{CHO}$ stretching and $\mathrm{C}-\mathrm{H}$ bending vibrations of the aldehyde group, respectively. The bands located at $\sim 1611$ and $\sim 1588 \mathrm{~cm}^{-1}$ were attributed to aromatic ring skeletal vibrations $(v)$, while those at $\sim 879, \sim 821$, and $\sim 779 \mathrm{~cm}^{-1}$ corresponded to o-, m-, and p-substituents on the aromatic ring, respectively. The peak at $1506 \mathrm{~cm}^{-1}$ was assigned to the $\mathrm{N}-\mathrm{H}$ bending vibrations $\left(v_{\mathrm{NH}}\right)$ in secondary amines. The $\mathrm{C}-\mathrm{N}$ stretching vibrations $\left(v_{\mathrm{C}-\mathrm{N}}\right)$ of aromatic secondary amines produced bands at 1241 and $1314 \mathrm{~cm}^{-1}$. The peaks observed at 
3645 and $686 \mathrm{~cm}^{-1}$ were attributed to $\mathrm{O}-\mathrm{H}$ stretching vibrations $\left(\nu_{\mathrm{OH}}\right)$ and $\mathrm{O}-\mathrm{H}$ curling vibrations $(\tau)$ in phenols, respectively. These data demonstrated that SHALOs were mixed with base oils comprising long-chain alkanes, saturated fatty acid esters, and additives, such as amines and phenols.

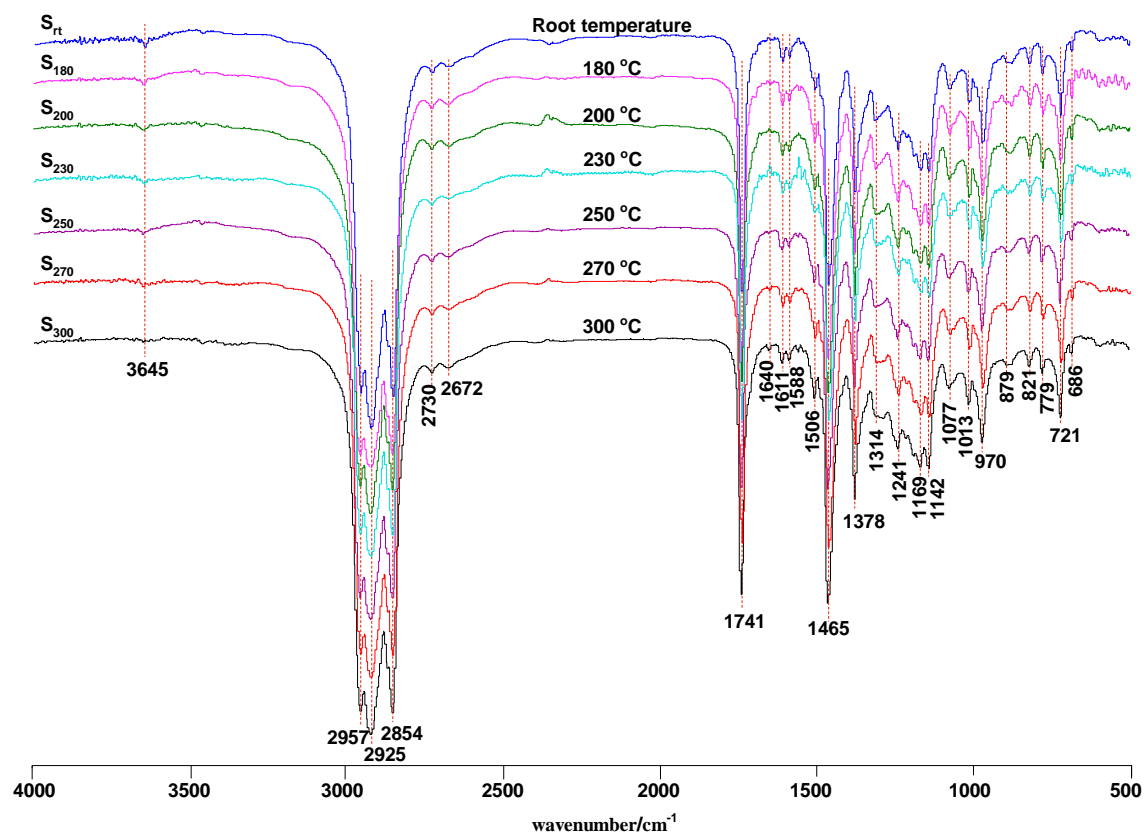

Figure 1. FT-IR spectra of $S_{r t}, S_{180}, S_{200}, S_{230}, S_{250}, S_{270}$, and $S_{300}$.

Table 1. FT-IR spectra assignments for $S_{r t}, S_{180}, S_{200}, S_{230}, S_{250}, S_{270}$, and $S_{300}$.

\begin{tabular}{|c|c|c|c|c|}
\hline Type & Group & $\begin{array}{l}\text { Characteristic } \\
\text { Frequency/cm }\end{array}$ & Intensity * & Belonging \\
\hline \multirow{6}{*}{ alkyl group } & $-\mathrm{CH}_{3}$ & 2957 & vs & $v^{\text {as }}$ \\
\hline & $-\mathrm{CH}_{2-}$ & 2925 & vs & $v^{\text {as }}$ \\
\hline & $-\mathrm{CH}_{2}-$ & 2854 & vs & $v^{\mathrm{s}}$ \\
\hline & $-\mathrm{CH}_{2}-$ & 1465 & vs & $\delta$ \\
\hline & $-\mathrm{CH}\left(\mathrm{CH}_{3}\right)_{2}$ & 1738 & $\mathrm{~s}$ & $\delta^{\text {as }}$ \\
\hline & $-\left(\mathrm{CH}_{2}\right)_{\mathrm{n}^{-}}$ & 721 & $\mathrm{~m}$ & $\delta$ \\
\hline \multirow{2}{*}{ aldehyde group } & $\mathrm{C}-\mathrm{H}$ & 2730 & $\mathrm{w}$ & $v_{\mathrm{CH}}$ \\
\hline & $\mathrm{C}-\mathrm{H}$ & 2672 & $\mathrm{w}$ & $\gamma$ \\
\hline \multirow{2}{*}{ ester } & $\mathrm{C}=\mathrm{O}$ & 1741 & vs & $v_{\mathrm{C}=\mathrm{O}}$ \\
\hline & $\begin{array}{l}\mathrm{C}-\mathrm{O}-\mathrm{C} \text { in long-chain } \\
\text { saturated fatty acids }\end{array}$ & 1169 and 1142 & $\mathrm{~m}$ & $v^{\text {as }}\left(\mathrm{C}^{-} \mathrm{O}^{-} \mathrm{C}\right)$ \\
\hline \multirow{4}{*}{ benzene } & framework vibrations & 1611 and 1588 & w & $v$ \\
\hline & $\mathrm{O}^{-}$ & 879 & $\mathrm{~m}$ & \\
\hline & $\mathrm{m}-$ & 821 & $\mathrm{~m}$ & $\gamma=\mathrm{C}-\mathrm{H}$ \\
\hline & $\mathrm{p}-$ & 779 & $\mathrm{~m}$ & \\
\hline \multirow{2}{*}{ olefin } & $\mathrm{C}=\mathrm{C}$ & 1640 & vw & $v_{C=C}$ \\
\hline & $=\mathrm{CH}-\mathrm{H}$ & 970 & $\mathrm{~s}$ & $\omega_{\mathrm{C}=\mathrm{C}}$ \\
\hline \multirow{2}{*}{ secondary amine } & $-\mathrm{NH}$ & 1506 & $\mathrm{w}$ & $v_{\mathrm{NH}}$ \\
\hline & $\begin{array}{l}\mathrm{C}-\mathrm{N} \text { in aromatic } \\
\text { compounds }\end{array}$ & 1241 and 1314 & $\mathrm{w}$ & $v_{\mathrm{C}-\mathrm{N}}$ \\
\hline \multirow{2}{*}{ phenol } & $-\mathrm{OH}$ & 3645 & $\mathrm{w}$ & $v_{\mathrm{OH}}$ \\
\hline & $\mathrm{O}-\mathrm{H}$ & 686 & $\mathrm{w}$ & $\tau$ \\
\hline
\end{tabular}


As shown in Figure 1 and Table 1, the FTIR spectra of the seven oil samples changed very little under high-temperature treatment. Strong absorbances at around 2957, 2925, 2854, 1741, 1465, 970, and $721 \mathrm{~cm}^{-1}$ suggested that long-chain alkanes, carbonyl compounds, and unsaturated hydrocarbons were still abundant in the aged oils. The $\mathrm{O}-\mathrm{H}$ stretching vibration located at $\sim 3645 \mathrm{~cm}^{-1}$ decreased as a function of TT temperature until the vibration was no longer detected, indicating that phenolic antioxidants were continuously consumed. The $C=C$ stretching vibration observed at $\sim 1640 \mathrm{~cm}^{-1}$ was only detected in $\mathrm{S}_{300}$, which suggested that long-chain hydrocarbons were broken into olefins (OFs) and other substances as a function of TT temperature. Thermal cracking and polymerization reactions were concluded to occur to varying degrees during the high-temperature treatment of SHALOs, with antioxidant consumption somewhat preventing the lubricating oil properties from diminishing.

\subsection{APC Analysis}

The relative molecular mass and corresponding mass distribution are among the most basic structural parameters of lubricating oils that are closely related to the physicochemical properties (such as KV and PP) and the thermal and tribological properties of the lubricating oil. The molecular mechanism of thermal stability can be explored using the molecular weight and corresponding mass distribution. APC is an effective method for measuring the molecular weight and molecular weight distribution of lubricating oils. APC can also obtain important molecular weight information, such as the weight-average molecular weight $\left(M_{w}\right)$ and number-average molecular weight $\left(M_{n}\right)$.

The SHALO used in this study contained a base oil comprising $80 \% \mathrm{PAO}, 20 \%$ diisooctyl adipate (DIOA), and a small number of additives. A previous study [36] has shown that PAO is polymerized and comprises linear $\alpha$-olefins ranging from trimers to pentamers. The PAO structure is relatively regular with a uniform comb-shaped isoparaffin (IP) chain length of generally $C_{8}-C_{10}$. Based on the $M_{W}$ of $\mathrm{S}_{\mathrm{rt}}$ being $507 \mathrm{Da}$ (Figure 2), the $\mathrm{M}_{\mathrm{W}}$ of PAO could be predicted to be $520 \mathrm{Da}$, with a molecular formula of $\mathrm{C}_{37} \mathrm{H}_{76}$. Combined with the PAO comb-shaped structure, the preliminary estimated structural formula of PAO is shown in Figure 3.

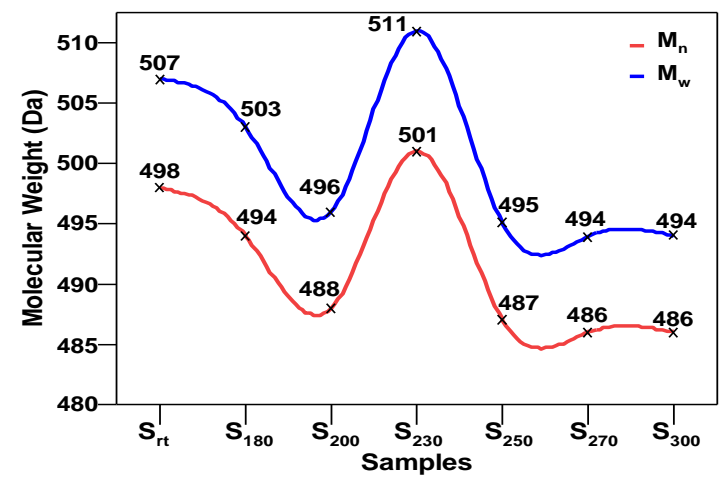

Figure 2. Molecular weight distributions of $S_{r t}, S_{180}, S_{200}, S_{230}, S_{250}, S_{270}$, and $S_{300}$.

As shown in Figure 2, $M_{n}$ and $M_{w}$ fluctuated as a function of temperature. $M_{n}$ and $M_{w}$ both decreased at 180 and $200{ }^{\circ} \mathrm{C}$, with values of 503 and $494 \mathrm{Da}$, and 496 and $488 \mathrm{Da}$, respectively. The highest $\mathrm{M}_{n}$ and $\mathrm{M}_{\mathrm{w}}$ values of 501 and $511 \mathrm{Da}$, respectively, were observed at $230^{\circ} \mathrm{C}$. Thereafter, $M_{n}$ and $M_{w}$ were again reduced and found to be stable at temperatures over $230^{\circ} \mathrm{C}$, with values of 495 and $487 \mathrm{Da}, 494$ and $486 \mathrm{Da}$, and 494 and $486 \mathrm{Da}$ for $\mathrm{S}_{250}, \mathrm{~S}_{270}$, and $\mathrm{S}_{300}$, respectively. There was insufficient thermal energy in the SHALOs to induce a larger degree of polymerization below $200{ }^{\circ} \mathrm{C}$, at which the $\mathrm{M}_{\mathrm{w}}$ was relatively low owing to the cracking degree being higher than the polymerization degree. In the range of $200-230^{\circ} \mathrm{C}$, increasing temperature caused larger-scale polymerization owing to TT, providing sufficient energy to significantly increase the $M_{w}$. Therefore, $M_{n}$ and $M_{w}$ reached peak values in $S_{230}$. The cracking degree was again higher than the polymerization degree when the temperature increased above $230{ }^{\circ} \mathrm{C}$. In contrast, the SHALOs were less able to dissolve the 
polymers, resulting in coking and sludge formation at high temperatures. Under these experimental conditions, the $\mathrm{M}_{\mathrm{w}}$ first decreased, then increased, and finally decreased again. The molecular weight distribution width index, $D\left(D=M_{w} / M_{n}\right)$, varied from 1.018 to 1.020 depending on the TT temperature, showing that the oil samples were narrow heterogeneous dispersion systems at each temperature.

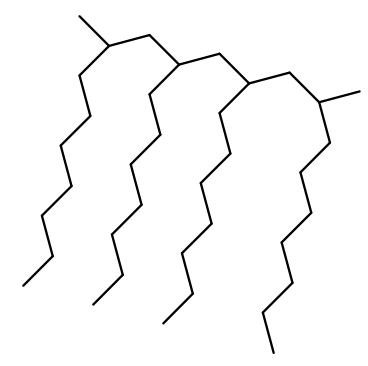

Figure 3. The possible structural formula of the poly- $\alpha$-olefin (PAO).

\subsection{GC/MS Analysis}

As shown in Figure 4, $\mathrm{S}_{\mathrm{rt}}$ was rich in two base oils (PAO and DIOA) and also contained four additives, three of which were antioxidants (butylated hydroxytoluene (BHT), N-phenyl- $\alpha$-naphthylamine (NPAN), 4-octyl-N-(4-octylphenyl) aniline (ODA)), while the other was an antiwear additive (tris(3-methylphenyl) phosphate (TMP)).

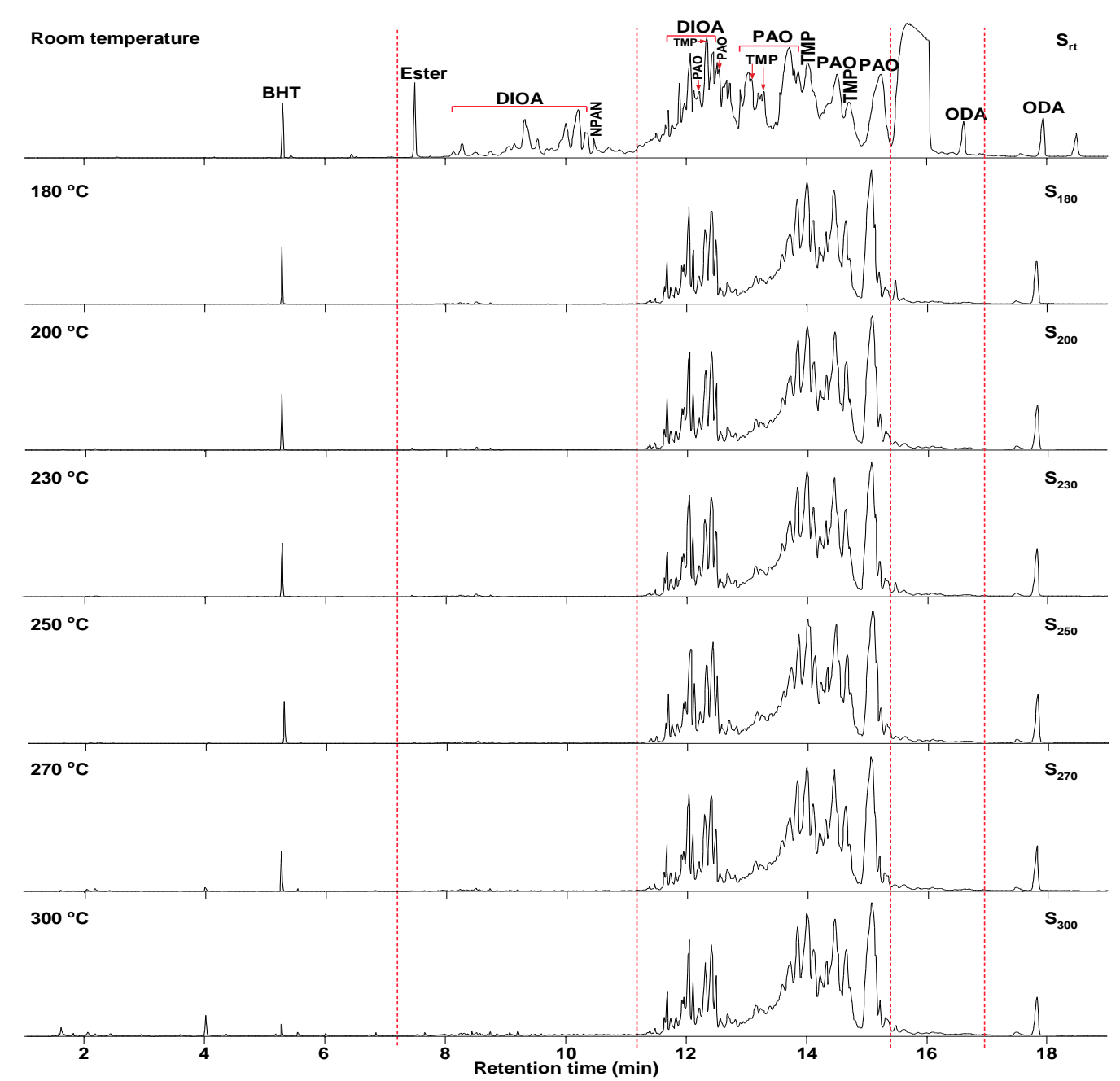

Figure 4. Total ion chromatograms (TIC) of the oil samples as a function of temperature. 
Figure 4 also shows significant differences in oil composition as a function of TT temperature. In contrast to $S_{r t}$, DIOA and NPAN were not detected in $S_{180}-S_{300}$ at retention times of 7-11 min and 15-17 min by GC/MS, respectively. Significant compositional differences existed between $S_{\mathrm{rt}}$ and $\mathrm{S}_{180}$, including a clear reduction in BHT, ODA, and TMP contents observed in $\mathrm{S}_{180}$. Furthermore, BHT and TMP were barely detected, together with an observed decrease in ODA in S300, implying that antioxidants were continuously removed from the system, preventing thermal cracking reactions. Furthermore, the compounds detected by GC/MS increased in intensity as a function of TT temperature over the first $11 \mathrm{~min}$. The free radicals generated by thermal oxidation during the service life of lubricants are suggested to first be consumed by free-radical trapping antioxidant NPAN (medium-temperature antioxidant), which hinders more severe oxidation reactions [37] and, therefore, maintains the normal lubrication function of the oil.

Cracking reactions were performed with the oil samples according to the variation and relative contents (RCs) of small-molecule compounds. As shown in Figure 5 and Table 2, 82 organic compounds were detected by GC/MS, which were classified into n-alkanes (NAs), eight IPs, 21 OFs, 24 ETs, three alcohols (AHs), eight antioxygen and other compounds (AOs), and two unknowns (UKs).

Twenty-seven compounds were identified in $\mathrm{S}_{\mathrm{rt}}$, including $23 \mathrm{ETs}$, three AOs, and one UK. Among them, ETs were the main components, accounting for the content of $10.90 \%$. The three antioxidants were BHT (22), NPAN (N), and BHT derivatives (19). Fifteen compounds were detected in $\mathrm{S}_{180}$, including three NAs, two OFs, four IPs, one AH, and five AOs. The RCs of BHT (22), 2-, 6-, 10-, and 14-tetramethylhexadecane (39), and eicosane (43) accounted for a higher percentage. The distribution of compounds comprising $S_{200}$ was similar to that of $S_{230}$. Twenty-two compounds were detected in both samples, including seven NAs, two OFs, four IPs, two AHs, and six AOs. The RCs of 4-methylheptan-1-ol (7), BHT (22), 3,5-di-tert-butyl-4-hydroxybenzaldehyde, eicosane (43), and (E)-2-methylnonadec-7-ene (47) accounted for a higher percentage. Thirty-one compounds were detected in $\mathrm{S}_{250}$, including $12 \mathrm{NAs}$, eight OFs, four IPs, two AHs, and five AOs. The RCs of 4-methylheptan-1-ol (7), 2-(tert-butyl)-4-methylphenol (12), BHT (22), and the isomer of BHT (24) accounted for a higher percentage. Thirty-seven compounds were detected in $\mathrm{S}_{270}$, including 15 NAs, $11 \mathrm{OFs}$, four IPs, two AHs, and five AOs. The RCs of decane (6), 2-(tert-butyl)-4-methylphenol (12), BHT (22), and the isomer of 22 (24) accounted for a higher percentage. Fifty-two compounds were detected in $\mathrm{S}_{300}$, including $16 \mathrm{NAs}, 21 \mathrm{OFs}$, and four AOs. The amounts of (Z)-oct-2-ene (4), 2-(tert-butyl)-4-methylphenol (12), the isomer of BHT (24), and NAs $\left(\mathrm{C}_{9}-\mathrm{C}_{21}\right)$ had obviously increased. However, the BHT (22) content was drastically reduced (>50\%) compared with that of $\mathrm{S}_{\mathrm{rt}}$.

The above results showed that temperature played an important role in the compounds detected and influenced the compound type and RC. As shown in Figures 4 and 5, at a retention time of 8-11 min, the RCs of DIOA and NPAN in $\mathrm{S}_{\mathrm{rt}}$ were high, but the same compounds were not detected in $\mathrm{S}_{180}$. Instead, BHT underwent basic structure unit degradation to yield a small number of hydrocarbons. (Z)-Oct-2-ene $\left(4, C_{8}\right)$, NAs $\left(6, C_{10} ; 21, C_{15}\right)$, and 4-methylheptan-1-ol $\left(7, C_{8}\right)$ were observed in $S_{200}$, while the other two BHT derivatives, namely, 2-(tert-butyl)-4-methylphenol (12) and the isomer of BHT (24), were detected in $\mathrm{S}_{230}$. When the temperature reached $250^{\circ} \mathrm{C}$, small-molecule compounds showed increased contents, with the appearance of additional NAs $\left(5, C_{9} ; 6, C_{10} ; 8, C_{11} ; 10, C_{12} ; 21\right.$, $\mathrm{C}_{15} ; 26, \mathrm{C}_{16}$ ). As shown in Figures 4 and 6 , when the temperature exceeded $270{ }^{\circ} \mathrm{C}$, the amount and $\mathrm{RC}$ of small molecular compounds in $\mathrm{S}_{300}$ gradually increased compared with the other TT oil samples, reaching 52 compounds and $4.600 \%$, respectively. This might be principally attributed to thermal cracking reactions of the base oils. Conversely, BHT, ODA, and TMP cracked only into relatively few small molecules through high-temperature oxidation. The results showed that the oil samples subjected to TT temperatures of $>230^{\circ} \mathrm{C}$ presented an increase in the number of small molecules, while the average molecular weight decreased, with concomitant deterioration in the properties. These observations were in agreement with the APC results. 


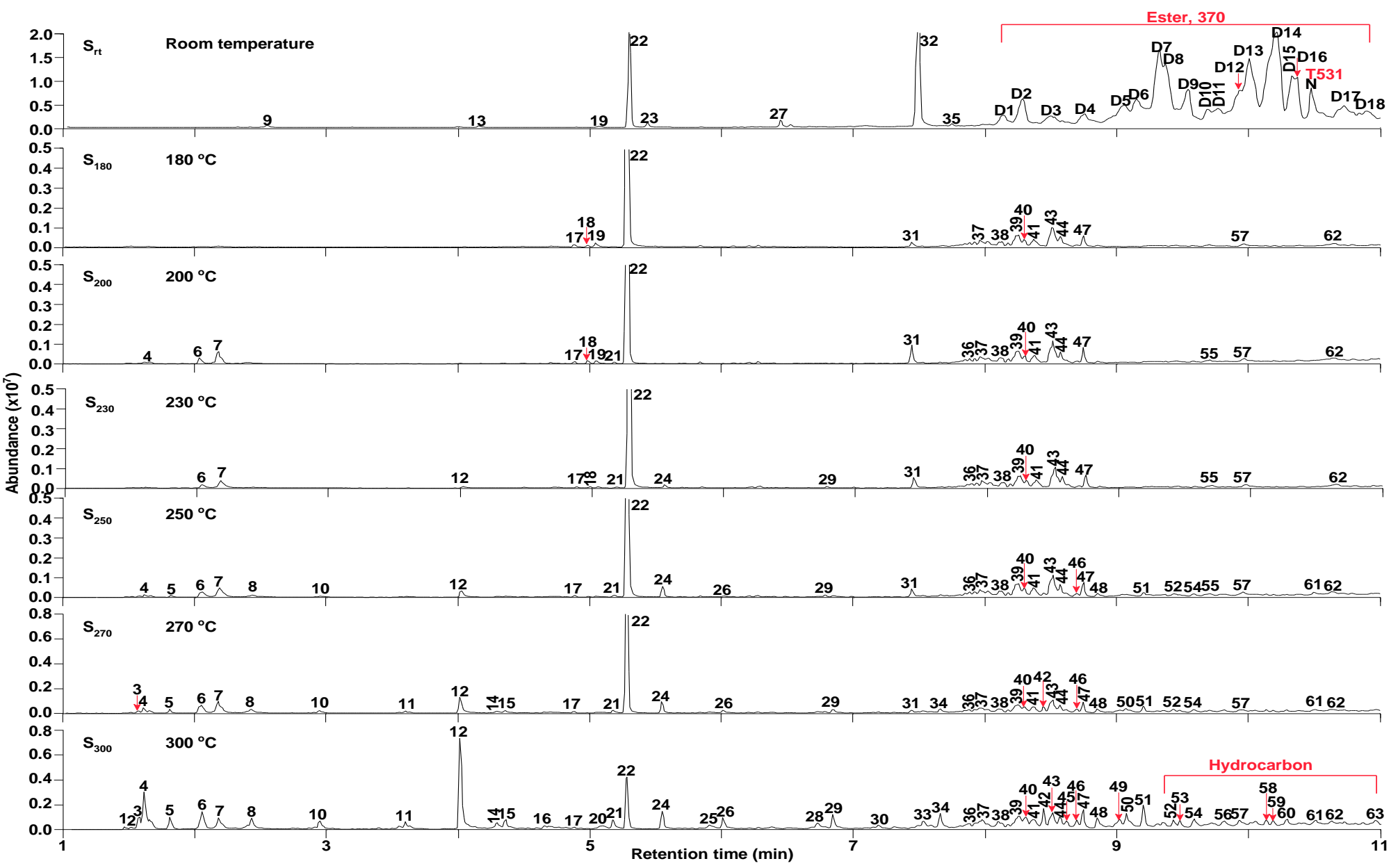

Figure 5. TICs of the oil samples as a function of temperature at retention times of 1-11 min. 
Table 2. Compounds detected in the total ion chromatograms of the oil samples as a function of temperature at retention times of 1-11 min.

\begin{tabular}{|c|c|c|c|c|c|c|c|c|c|c|c|c|}
\hline \multirow{2}{*}{ Peak } & \multirow{2}{*}{$\begin{array}{l}\text { Retention } \\
\text { Time (min) }\end{array}$} & \multirow{2}{*}{ Compounds } & \multirow{2}{*}{$\begin{array}{l}\text { Chemical } \\
\text { Formula }\end{array}$} & \multirow{2}{*}{$\begin{array}{l}\text { Molecular } \\
\text { Weight }\end{array}$} & \multirow{2}{*}{$\begin{array}{l}\text { Structural } \\
\text { Formula }\end{array}$} & \multicolumn{7}{|c|}{ Relative Content (\%) } \\
\hline & & & & & & $\mathrm{S}_{\mathrm{rt}}$ & $\mathrm{S}_{180}$ & $\mathrm{~S}_{200}$ & $S_{230}$ & $\mathrm{~S}_{250}$ & $S_{270}$ & $S_{300}$ \\
\hline 1 & 1.468 & 1-Butene & $\mathrm{C}_{4} \mathrm{H}_{8}$ & 56 & & - & - & - & - & - & - & 0.015 \\
\hline 2 & 1.518 & Hexane & $\mathrm{C}_{6} \mathrm{H}_{14}$ & 86 & & - & - & - & - & - & - & 0.012 \\
\hline 3 & 1.579 & 3-methylhept-1-ene & $\mathrm{C}_{8} \mathrm{H}_{16}$ & 112 & & - & - & - & - & - & 0.006 & 0.094 \\
\hline 4 & 1.615 & (Z)-oct-2-ene & $\mathrm{C}_{8} \mathrm{H}_{16}$ & 112 & & - & - & 0.018 & - & 0.011 & 0.016 & 0.163 \\
\hline 5 & 1.814 & Nonane & $\mathrm{C}_{9} \mathrm{H}_{20}$ & 128 & & - & - & - & - & 0.011 & 0.013 & 0.084 \\
\hline 6 & 2.057 & Decane & $\mathrm{C}_{10} \mathrm{H}_{22}$ & 142 & & - & - & 0.028 & 0.024 & 0.044 & 0.042 & 0.168 \\
\hline 7 & 2.182 & 4-methylheptan-1-ol & $\mathrm{C}_{8} \mathrm{H}_{18} \mathrm{O}$ & 130 & & - & - & 0.086 & 0.066 & 0.087 & 0.058 & 0.122 \\
\hline 8 & 2.432 & Undecane & $\mathrm{C}_{11} \mathrm{H}_{24}$ & 156 & & - & - & - & - & 0.024 & 0.021 & 0.12 \\
\hline 9 & 2.547 & 2-ethylhexyl pentanoate & $\mathrm{C}_{13} \mathrm{H}_{26} \mathrm{O}_{2}$ & 214 & & 0.024 & - & - & - & - & - & - \\
\hline 10 & 2.948 & Dodecane & $\mathrm{C}_{12} \mathrm{H}_{26}$ & 170 & & - & - & - & - & 0.009 & 0.01 & 0.083 \\
\hline 11 & 3.601 & Tridecane & $\mathrm{C}_{13} \mathrm{H}_{28}$ & 184 & & - & - & - & - & - & 0.007 & 0.027 \\
\hline 12 & 4.015 & 2-(tert-butyl)-4-methylphenol & $\mathrm{C}_{11} \mathrm{H}_{16} \mathrm{O}$ & 164 & & - & - & - & 0.009 & 0.038 & 0.059 & 0.646 \\
\hline 13 & 4.157 & 2-ethylhexyl hexanoate & $\mathrm{C}_{14} \mathrm{H}_{28} \mathrm{O}_{2}$ & 228 & & 0.013 & - & - & - & - & - & - \\
\hline 14 & 4.295 & (E)-tetradec-5-ene & $\mathrm{C}_{14} \mathrm{H}_{28}$ & 196 & & - & - & - & - & - & 0.008 & 0.063 \\
\hline 15 & 4.358 & Tetradecane & $\mathrm{C}_{14} \mathrm{H}_{30}$ & 198 & & - & - & - & - & - & 0.009 & 0.086 \\
\hline 16 & 4.656 & pentylpentanoate & $\mathrm{C}_{10} \mathrm{H}_{20} \mathrm{O}_{2}$ & 172 & & - & - & - & - & - & - & 0.018 \\
\hline 17 & 4.883 & 3-(tert-butyl)-4-methoxyphenol & $\mathrm{C}_{11} \mathrm{H}_{16} \mathrm{O}_{2}$ & 180 & & - & 0.009 & 0.008 & 0.005 & 0.008 & 0.005 & 0.013 \\
\hline 18 & 4.981 & $\begin{array}{c}\text { 2,6-di-tert-butylcyclohexa-2,5 } \\
\text {-diene-1,4-dione }\end{array}$ & $\mathrm{C}_{14} \mathrm{H}_{20} \mathrm{O}_{2}$ & 220 & & - & 0.005 & 0.012 & 0.005 & - & - & - \\
\hline
\end{tabular}


Table 2. Cont.

\begin{tabular}{|c|c|c|c|c|c|c|c|c|c|c|c|c|}
\hline \multirow{2}{*}{ Peak } & \multirow{2}{*}{$\begin{array}{l}\text { Retention } \\
\text { Time (min) }\end{array}$} & \multirow{2}{*}{ Compounds } & \multirow{2}{*}{$\begin{array}{l}\text { Chemical } \\
\text { Formula }\end{array}$} & \multirow{2}{*}{$\begin{array}{l}\text { Molecular } \\
\text { Weight }\end{array}$} & \multirow{2}{*}{$\begin{array}{l}\text { Structural } \\
\text { Formula }\end{array}$} & \multicolumn{7}{|c|}{ Relative Content (\%) } \\
\hline & & & & & & $\mathrm{S}_{\mathrm{rt}}$ & $\mathrm{S}_{180}$ & $S_{200}$ & $\mathrm{~S}_{230}$ & $\mathrm{~S}_{250}$ & $S_{270}$ & $S_{300}$ \\
\hline 19 & 5.064 & 4,4,5,7,8-pentamethylchroman-2-one & $\mathrm{C}_{14} \mathrm{H}_{18} \mathrm{O}_{2}$ & 218 & & 0.014 & 0.019 & 0.016 & - & - & - & - \\
\hline 20 & 5.096 & (E)-tetradec-5-ene & $\mathrm{C}_{14} \mathrm{H}_{28}$ & 196 & & - & - & - & - & - & - & 0.055 \\
\hline 21 & 5.175 & Pentadecane & $\mathrm{C}_{15} \mathrm{H}_{32}$ & 212 & & - & - & 0.007 & 0.005 & 0.01 & 0.007 & 0.083 \\
\hline 22 & 5.281 & 2,6-di-tert-butyl-4-methylphenol & $\mathrm{C}_{15} \mathrm{H}_{24} \mathrm{O}$ & 220 & & 0.833 & 1.692 & 1.402 & 1.472 & 1.13 & 0.492 & 0.363 \\
\hline 23 & 5.434 & 2-methylbutyl heptanoate & $\mathrm{C}_{12} \mathrm{H}_{24} \mathrm{O}_{2}$ & 200 & & 0.049 & - & - & - & - & - & - \\
\hline 24 & 5.550 & isomer of 22 & $\mathrm{C}_{15} \mathrm{H}_{24} \mathrm{O}$ & 220 & 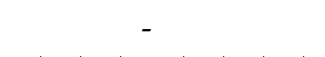 & - & - & - & 0.002 & 0.043 & 0.03 & 0.123 \\
\hline 25 & 5.909 & (Z)-hexadec-7-ene & $\mathrm{C}_{16} \mathrm{H}_{32}$ & 224 & M & - & - & - & - & - & - & 0.042 \\
\hline 26 & 6.013 & Hexadecane & $\mathrm{C}_{16} \mathrm{H}_{34}$ & 226 & & - & - & - & - & 0.004 & 0.011 & 0.085 \\
\hline 27 & 6.446 & 2-ethylhexyl 2-methoxyacetate & $\mathrm{C}_{11} \mathrm{H}_{22} \mathrm{O}_{3}$ & 202 & & 0.064 & - & - & - & - & - & - \\
\hline 28 & 6.729 & (E)-heptadec-8-ene & $\mathrm{C}_{17} \mathrm{H}_{34}$ & 238 & & - & - & - & - & - & - & 0.062 \\
\hline 29 & 6.846 & Heptadecane & $\mathrm{C}_{17} \mathrm{H}_{36}$ & 240 & & - & - & - & 0.006 & 0.009 & 0.017 & 0.112 \\
\hline 30 & 7.192 & 7,9-dimethylhexadecane & $\mathrm{C}_{18} \mathrm{H}_{38}$ & 254 & & - & - & - & - & - & - & 0.017 \\
\hline 31 & 7.443 & $\begin{array}{l}\text { 3,5-di-tert-butyl-4- } \\
\text { hydroxybenzaldehyde }\end{array}$ & $\mathrm{C}_{15} \mathrm{H}_{22} \mathrm{O}_{2}$ & 234 & & - & 0.019 & 0.075 & 0.048 & 0.035 & 0.013 & - \\
\hline 32 & 7.493 & 2-ethylhexyl isobutyl carbonate & $\mathrm{C}_{13} \mathrm{H}_{26} \mathrm{O}_{3}$ & 230 & & 1.427 & - & - & - & - & - & - \\
\hline 33 & 7.534 & (E)-octadec-9-ene & $\mathrm{C}_{18} \mathrm{H}_{36}$ & 252 & $M m$ & - & - & - & - & - & - & 0.053 \\
\hline 34 & 7.661 & Octadecane & $\mathrm{C}_{18} \mathrm{H}_{38}$ & 254 & & - & - & - & - & - & 0.016 & 0.096 \\
\hline 35 & 7.747 & unknown & - & - & - & 0.021 & - & - & - & - & - & - \\
\hline
\end{tabular}


Table 2. Cont.

\begin{tabular}{|c|c|c|c|c|c|c|c|c|c|c|c|c|}
\hline \multirow{2}{*}{ Peak } & \multirow{2}{*}{$\begin{array}{l}\text { Retention } \\
\text { Time (min) }\end{array}$} & \multirow{2}{*}{ Compounds } & \multirow{2}{*}{$\begin{array}{l}\text { Chemical } \\
\text { Formula }\end{array}$} & \multirow{2}{*}{$\begin{array}{l}\text { Molecular } \\
\text { Weight }\end{array}$} & \multirow{2}{*}{$\begin{array}{l}\text { Structural } \\
\text { Formula }\end{array}$} & \multicolumn{7}{|c|}{ Relative Content (\%) } \\
\hline & & & & & & $S_{\mathrm{rt}}$ & $\mathrm{S}_{180}$ & $S_{200}$ & $S_{230}$ & $\mathrm{~S}_{250}$ & $S_{270}$ & $\mathrm{~S}_{300}$ \\
\hline 36 & 7.880 & (Z)-nonadec-5-ene & $\mathrm{C}_{19} \mathrm{H}_{38}$ & 266 & - & - & - & 0.011 & 0.007 & 0.009 & 0.017 & - \\
\hline 37 & 7.979 & 10-methylnonadecane & $\mathrm{C}_{20} \mathrm{H}_{42}$ & 282 & & - & 0.007 & 0.02 & 0.022 & 0.022 & 0.025 & 0.128 \\
\hline 38 & 8.099 & nonadec-1-ene & $\mathrm{C}_{19} \mathrm{H}_{38}$ & 266 & & - & 0.022 & 0.032 & 0.016 & 0.03 & 0.023 & 0.067 \\
\hline 39 & 8.259 & 2,6,10,14-tetramethylhexadecane & $\mathrm{C}_{20} \mathrm{H}_{42}$ & 282 & & - & 0.007 & 0.083 & 0.069 & 0.081 & 0.063 & 0.113 \\
\hline 40 & 8.310 & 2-(hexadecyloxy)ethan-1-ol & $\mathrm{C}_{18} \mathrm{H}_{38} \mathrm{O}_{2}$ & 286 & & - & 0.022 & 0.028 & 0.027 & 0.034 & 0.021 & 0.072 \\
\hline 41 & 8.367 & 4-methylnonadecane & $\mathrm{C}_{20} \mathrm{H}_{42}$ & 282 & & - & 0.05 & 0.05 & 0.051 & 0.048 & 0.03 & 0.087 \\
\hline 42 & 8.445 & Nonadecane & $\mathrm{C}_{19} \mathrm{H}_{40}$ & 268 & & - & - & - & - & - & 0.02 & 0.103 \\
\hline 43 & 8.514 & Eicosane & $\mathrm{C}_{20} \mathrm{H}_{42}$ & 282 & - & - & 0.155 & 0.15 & 0.15 & 0.128 & 0.075 & 0.116 \\
\hline 44 & 8.571 & 2,3-dimethylnonadecane & $\mathrm{C}_{21} \mathrm{H}_{44}$ & 296 & & - & 0.065 & 0.067 & 0.036 & 0.043 & 0.034 & 0.057 \\
\hline 45 & 8.620 & 2-hexyldecan-1-ol & $\mathrm{C}_{16} \mathrm{H}_{34} \mathrm{O}$ & 242 & & - & - & - & - & - & - & 0.055 \\
\hline 46 & 8.697 & unknown & - & - & - & - & - & - & - & 0.01 & 0.019 & 0.042 \\
\hline 47 & 8.745 & (E)-2-methylnonadec-7-ene & $\mathrm{C}_{20} \mathrm{H}_{40}$ & 280 & & - & 0.048 & 0.058 & 0.055 & 0.06 & 0.039 & 0.116 \\
\hline 48 & 8.854 & icos-1-ene & $\mathrm{C}_{20} \mathrm{H}_{40}$ & 280 & - & - & - & - & - & 0.017 & 0.018 & 0.085 \\
\hline 49 & 9.022 & (E)-icos-9-ene & $\mathrm{C}_{20} \mathrm{H}_{40}$ & 280 & & - & - & - & - & - & - & 0.076 \\
\hline 50 & 9.073 & (E)-icos-5-ene & $\mathrm{C}_{20} \mathrm{H}_{40}$ & 280 & - & - & - & - & - & - & 0.03 & 0.123 \\
\hline 51 & 9.203 & Heneicosane & $\mathrm{C}_{21} \mathrm{H}_{44}$ & 296 & - & - & - & - & - & 0.014 & 0.032 & 0.152 \\
\hline 52 & 9.431 & olefin $(C \geq 21)$ & & & & - & - & - & - & 0.016 & 0.023 & 0.04 \\
\hline 53 & 9.481 & isoparaffin $(C \geq 21)$ & & & & - & - & - & - & - & - & 0.047 \\
\hline 54 & 9.589 & olefin $(C \geq 21)$ & & & & - & - & - & - & 0.015 & 0.022 & 0.072 \\
\hline 55 & 9.690 & isoparaffin $(C \geq 21)$ & & & & - & - & 0.017 & 0.019 & 0.024 & - & - \\
\hline 56 & 9.821 & olefin $(C \geq 21)$ & & & & - & - & - & - & - & - & 0.04 \\
\hline 57 & 9.936 & normal alkane $(C \geq 21)$ & - & - & - & - & 0.024 & 0.02 & 0.023 & 0.031 & 0.026 & 0.064 \\
\hline 58 & 10.137 & olefin $(C \geq 21)$ & & & & - & - & - & - & - & - & 0.037 \\
\hline 59 & 10.188 & isoparaffin $(C \geq 21)$ & & & & - & - & - & - & - & - & 0.032 \\
\hline 60 & 10.291 & olefin $(C \geq 21)$ & & & & - & - & - & - & - & - & 0.053 \\
\hline 61 & 10.511 & olefin $(C \geq 21)$ & & & & - & - & - & - & 0.015 & - & 0.062 \\
\hline 62 & 10.631 & normal alkane $(C \geq 21)$ & & & & - & 0.015 & - & 0.027 & 0.021 & - & 0.033 \\
\hline 63 & 10.967 & olefin $(C \geq 21)$ & & & & - & - & - & - & - & - & 0.077 \\
\hline D1-D18 & 8.135-10.893 & dioctylhexanedioate & $\mathrm{C}_{22} \mathrm{H}_{42} \mathrm{O}_{4}$ & 370 & - & 10.155 & - & - & - & - & - & - \\
\hline $\mathbf{N}$ & 10.549 & N-phenylnaphthalen-1-amine & $\mathrm{C}_{16} \mathrm{H}_{13} \mathrm{~N}$ & 219 & & 0.450 & - & - & - & - & - & - \\
\hline
\end{tabular}




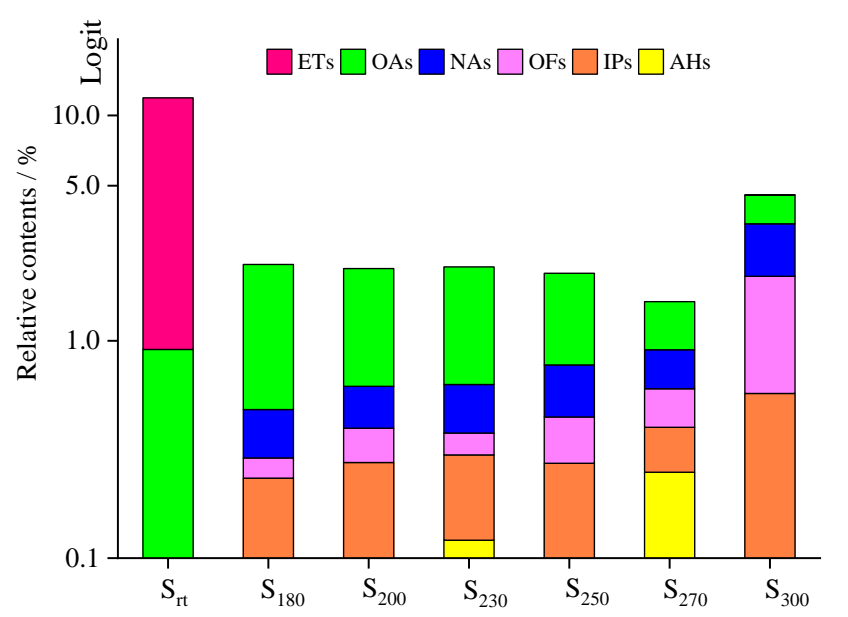

Figure 6. Distribution of group components in $\mathrm{S}_{\mathrm{rt}}$ and $\mathrm{S}_{180}-\mathrm{S}_{300}$.

\section{Discussion}

\subsection{Physicochemical Properties: Changes with Temperature}

As shown in Figure 7 , the $\mathrm{KV}$ at $40{ }^{\circ} \mathrm{C}\left(v_{40}\right), \mathrm{PP}, \mathrm{AN}$, and color showed different variational trends as a function of temperature. Changes in the trends of $v_{40}$, PP, and AN occurred at an inflection point of $250{ }^{\circ} \mathrm{C}$. When the temperature was $<250{ }^{\circ} \mathrm{C}$, the $v_{40}$, PP, and AN values of the samples were relatively stable. The ranges of variation for $v_{40}, \mathrm{PP}$, and AN were $14.6-14.4 \mathrm{~mm}^{2} / \mathrm{s},-65$ to $-69{ }^{\circ} \mathrm{C}$, and $0.07-0.45 \mathrm{mg} \mathrm{KOH} / \mathrm{g}$, respectively. When the temperature was $>250{ }^{\circ} \mathrm{C}$, the $v_{40}$, $\mathrm{PP}$, and AN values of the samples changed dramatically. The $v_{40}$ values of $S_{270}$ and $S_{300}$ were reduced to 14.1 and 13.5 $\mathrm{mm}^{2} / \mathrm{s}$, while the PP value was increased to -56 and $-27^{\circ} \mathrm{C}$, and the AN value was increased to 0.8 and $3.5 \mathrm{mg} \mathrm{KOH} / \mathrm{g}$, respectively.
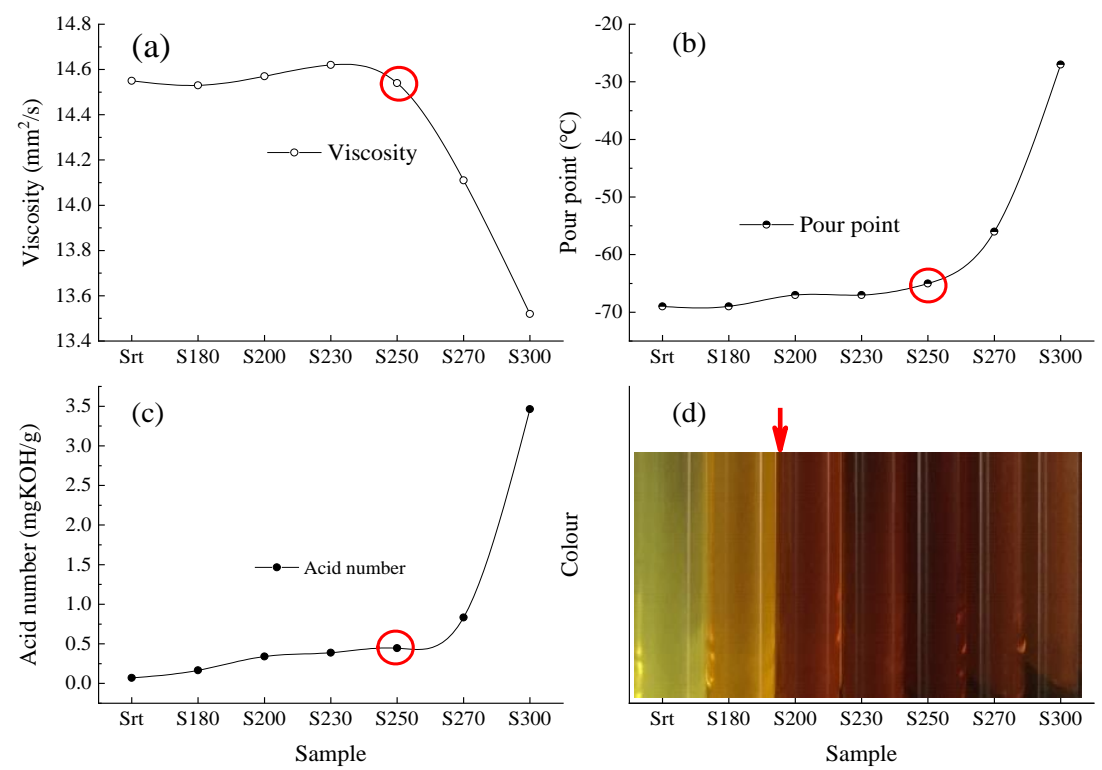

Figure 7. Kinematic viscosity at $40{ }^{\circ} \mathrm{C}$, pour point, acid number, and color of the oil samples as a function of temperature. (a) Kinematic viscosity; (b) Pour point; (c) Acid number; (d) Colour.

As shown in Figure 7, the inflection point for color was $200^{\circ} \mathrm{C}$. When subjected to TT temperatures of $>200{ }^{\circ} \mathrm{C}$, the oil samples were brown and black, while those at $180{ }^{\circ} \mathrm{C}$ were light brown. Compared with $v_{40}, \mathrm{PP}$, and $\mathrm{AN}$, the color was more sensitive to temperature, which induced rapid changes in the oil color. The color change preceded the degradation of the oil sample during 
the heating process and was relatively small during subsequent heating. Therefore, the color change should not be used as a basis for the degradation performance of the oil sample. Basing changes in the lubricating function of the oil solely on color changes is not ideal because the performance of the oil might not have actually deteriorated, resulting in waste. Studies have shown that changes in the oil color are related to the antioxidant effect of antioxidants [38]. The change in AN was derived from oxygen-containing compounds, such as alcohols, ketones, aldehydes, and acid esters, generated during high-temperature thermal oxidation [39]. PP is principally related to the $\alpha$-methylene content in alkyl groups and aromatic or naphthenic rings. The NAs exhibit a higher PP, while the IPs exhibit a lower PP [40]. During the low- and medium-temperature stages $\left(<250{ }^{\circ} \mathrm{C}\right)$, the antioxidant effect, while changing the color of the oil samples, also prevented the cracking of the PAO and DIOA molecular chains in the oil samples and, to a certain extent, the formation of other substances [41]. Therefore, the degradation rate of $v_{40}, \mathrm{PP}$, and AN at this stage was reduced. At the high-temperature stage $\left(>250{ }^{\circ} \mathrm{C}\right)$, the molecular structure of PAO was destroyed, and the type and content of n-alkanes exceeded that of o-alkanes, leading to an increase in PP [42]. Simultaneously, with the decrease in antioxidant content, the antioxidant effect was obviously weakened. The oil samples were typically subjected to high-temperature thermal oxidation and cracking, and the contents of small molecular oxygen-containing compounds, such as alcohols, ketones, aldehydes, and acid esters, significantly increased, leading to an increase in AN.

The KV of the lubricating oil is mainly derived from the interaction force between molecules. The distance between the molecules increases with rising temperature owing to volume expansion, which results in the decrease in force between molecules and, therefore, a decrease in viscosity. The small molecular compounds produced by cracking at high temperatures have made a greater contribution to the reduction in KV [43]. Based on the APC results, at $>230{ }^{\circ} \mathrm{C}$, the temperature was known to rapidly decrease both $\mathrm{M}_{\mathrm{n}}$ and $\mathrm{M}_{\mathrm{w}}$. Therefore, the relative number of small-molecule compounds increased, which led to a decrease in $v_{40}$ at high temperatures.

\subsection{Molecular Structure: Changes with Temperature}

The molecular structure of SLOs determines the thermal oxidation stability when oils are exposed to harsh operating conditions [2,44]. As shown in Figures 6 and 8, there were significant differences in the species and RCs of compounds detected by GC/MS between the fresh oil and aged oils. The fresh oil $\left(\mathrm{S}_{\mathrm{rt}}\right)$ comprised 23 ETs $(10.90 \%)$ and three AOs $(0.913 \%)$, while hydrocarbons, alcohols, and $\mathrm{AO}$ compounds were the main compounds observed in the aged oils $\left(\mathrm{S}_{180}-\mathrm{S}_{300}\right)$. ETs were not detected in $S_{180}-S_{270}$, but pentylpentanoate was observed in $S_{300}$. Degradation products were produced during the test, implying that the SHALO thermal oxidation process was highly complex. Meanwhile, any small changes in the experimental conditions, such as the experimental reactor, heating and cooling conditions, sampling approaches, and production batches of the same lubricating oils, could affect the results and the changing trend under high temperatures.

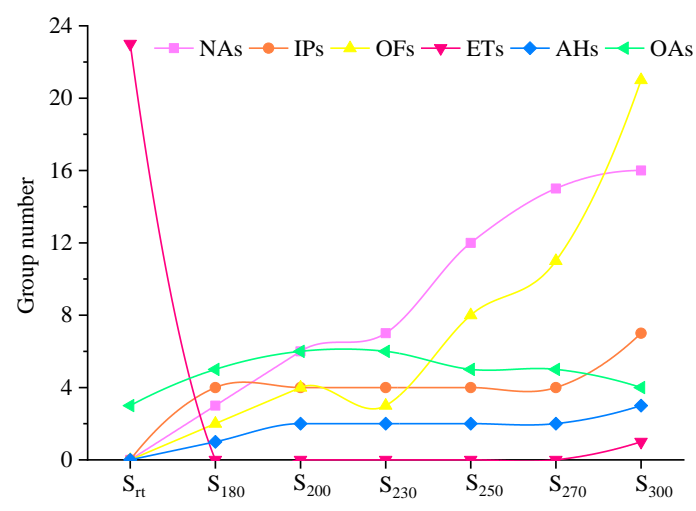

Figure 8. Group component numbers in $\mathrm{S}_{\mathrm{rt}}$ and $\mathrm{S}_{180}-\mathrm{S}_{300}$. 
The oxidation process of lubricating oils has three stages [26]. First, the antioxidant and antiwear additives are consumed, followed by oxidative degradation of the base oil, and, finally, polymerization, which leads to an increase in the oil viscosity in the final stage. The APC and GC/MS data were in agreement with the three stages of oxidation. The additives were depleted at $180{ }^{\circ} \mathrm{C}$ in the first stage. The RCs of the three antioxidants (BHT, NPAN, and ODA) and one antiwear additive (TMP) were reduced, but the amount of these compounds increased. Four derivatives of BHT are shown in Figure 9, and the number of carbon atoms associated with the NAs in $S_{180}$ was not less than 20. Generally, small-molecule compounds, which increased in content during degradation of the lubricating oil, resulted in decreased $\mathrm{M}_{\mathrm{n}}$ and $\mathrm{M}_{\mathrm{w}}$ values, while cross-linking and polycondensation of the compounds resulted in increased $\mathrm{M}_{\mathrm{n}}$ and $\mathrm{M}_{\mathrm{w}}$ values. Furthermore, decane was detected in $\mathrm{S}_{180}$. The oil samples at $<200^{\circ} \mathrm{C}$ were concluded to be partially pyrolyzed, as characterized by a growing amount of small-molecule compounds compared with that of macromolecules. The KV values of $S_{180}$ and $S_{200}$ were relatively low, suggesting that the formation of hydroperoxides in the initial oxidation period seriously deteriorated the properties of the aging oils. In the temperature range of $200-230^{\circ} \mathrm{C}$, the degree of polycondensation was greater than that of cracking in the aged oils owing to a growing volume of macromolecular compounds, while the KV of $S_{230}$ was observed to increase [45-47]. During this stage, the formation of polar organic compounds in the oil (such as ketones, alcohols, carboxylic acids, and esters) was more pronounced, with 4-methylheptan-1-ol and 2-(hexadecyloxy)ethan-1-ol detected. Furthermore, two new derivatives of BHT-2-(tert-butyl)-4-methylphenol and the isomer of BHT-were present in $\mathrm{S}_{230}$. The possible reaction phenolic hydroxyl oxygen pathways of BHT are shown in Figure 10. When heated, BHT acted as a radical terminator. The phenolic hydroxyl oxygen could participate in the benzene conjugated system to induce electronegativity, with the pushing of electron density from the $\mathrm{O}-, \mathrm{m}-$-, and $\mathrm{p}$-substituents resulting in a reduction of $\mathrm{O}-\mathrm{H}$ polarity. Hydrogen atoms were quickly abstracted by the free radicals of the lubricating oils to improve the thermal oxidation stability. The change in the composition of the SHALO was similar to the three-stage oxidation process (depletion of additives, degradation of the base oil, and polymerization) when the TT temperature was $<230{ }^{\circ} \mathrm{C}$. In the temperature range of $250-300{ }^{\circ} \mathrm{C}$, the degree of thermal cracking in the oil sample was greater than that of thermal polycondensation, characterized by a growing amount of small-molecule compounds. $\mathrm{C}_{10}-\mathrm{C}_{18}$ compounds were detected in $\mathrm{S}_{250}-\mathrm{S}_{300}$, and the RC of BHT derivative 2-(tert-butyl)-4-methylphenol increased from $0.009 \%$ in $S_{230}$ to $0.646 \%$ in $S_{300}$. Therefore, the KV of the aged oils was also significantly reduced $[2,13]$.

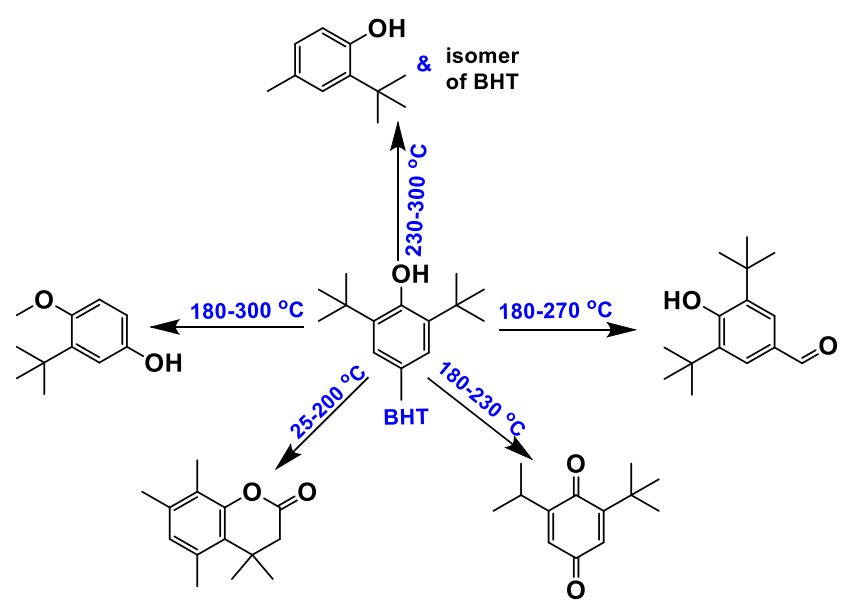

Figure 9. Butylated hydroxytoluene (BHT) derivative distributions. 


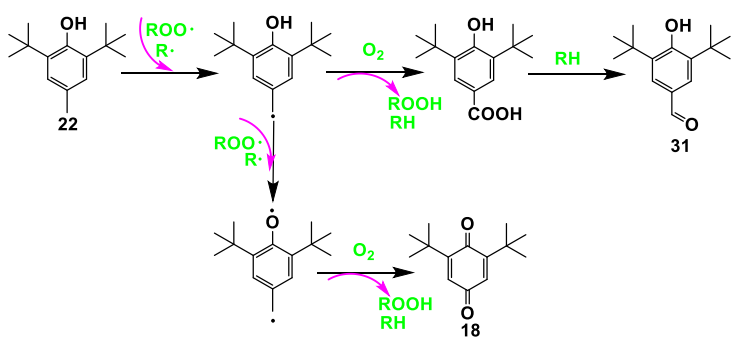

(a) The possible pathway 1

(a)

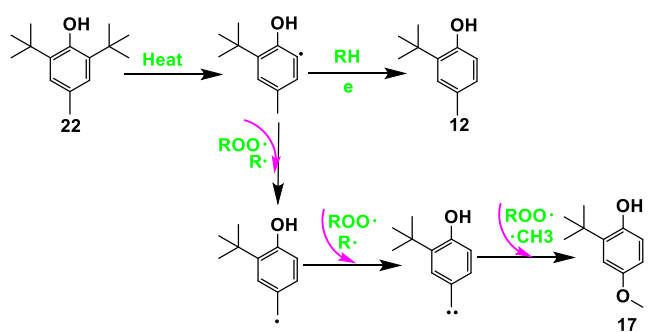

(b) The possible pathway 2

(b)

Figure 10. Possible reaction pathways of BHT. (a)The possible pathway 1; (b) The possible pathway 2.

Overall, the polycondensation and cracking reactions of the oil samples were shown to occur simultaneously at high temperatures, with thermal cracking as the predominant mechanism of these reactions (Figure 11). There was a significant difference between the degree of polycondensation and cracking reactions as a function of temperature. After polycondensation and pyrolysis reactions, the physicochemical properties of the oil samples changed, with the thermal stability decreasing to the degree that resulted in the deterioration of these properties. The results showed that at temperatures of $<250{ }^{\circ} \mathrm{C}$, the compounds in the base oil were slightly cracked, and the antioxidants significantly changed. Polycondensation is the predominant reaction below $250{ }^{\circ} \mathrm{C}$, which might explain why lower wear was observed for the aged oils compared with fresh oil, and why the films formed from the aged oils provided superior wear performance compared with that of the film formed from fresh oil [24]. When the temperature exceeded $250^{\circ} \mathrm{C}$, the compounds present in the oil samples were mainly pyrolyzed, but the antioxidant effect was less obvious. Furthermore, the types of small-molecule compounds increased, and a large number of small-molecule compounds, such as OFs and NAs, appeared. There were a large number of small molecular compounds, which indicated that a significant degree of thermal oxidation cracking occurred in the lubricating oil. Therefore, the molecular weight exhibited a downward trend, the viscosity decreased, and the oil film was not able to reach a certain thickness $(\leq 0.01 \mu \mathrm{m})$ [16]. The lubricating function of the lubricating oil was significantly impacted, with friction and wear occurring, leading to the deterioration of the oil properties.

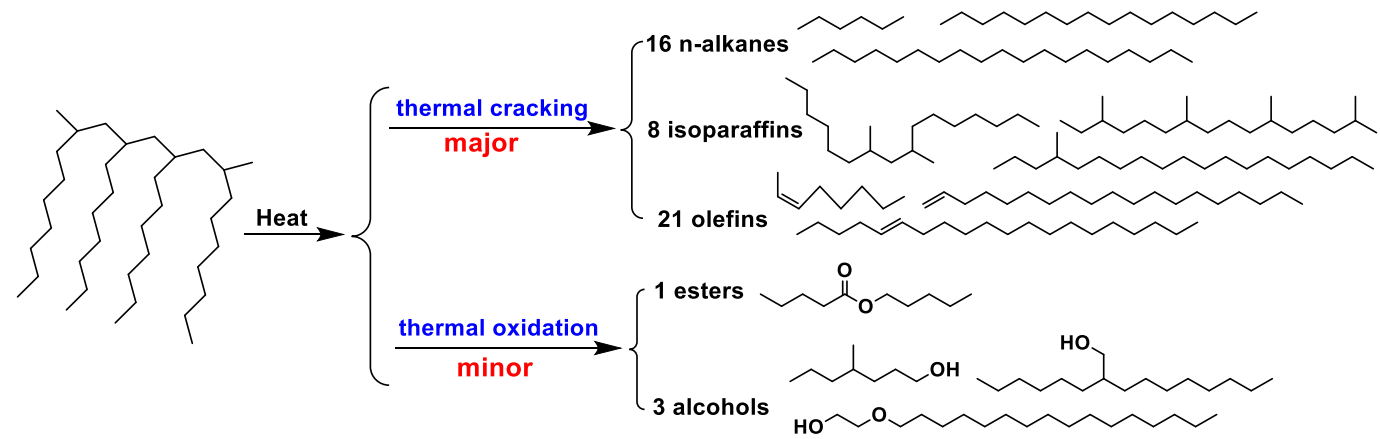

Figure 11. Possible reaction types of PAO.

\subsection{CA of the Oil Samples}

Clustering aims to seek natural groupings in the data based on the similarity of individual components or objects, such that the objects of the same group, or cluster, are more similar than different groups [48-50]. CA is considered a principal task of data exploration, is a common technique for statistical analysis and chemometric approaches, and is widely used in molecular spectroscopy [51-53]. The results of CA were intended to elucidate the compound structure and compositional changes of SHALOs resulting from oxidative high-temperature degradation, allowing detection of the degradation stages of SHALOs and signaling of the need for an oil change when warranted by the oil conditions [54]. 
Furthermore, the SHALO clusters could be used to detect possible relationships between compound structure and compositional changes at the molecular level and, therefore, facilitate the discovery of physicochemical properties at the macro level.

Based on 82 compounds detected from seven samples by GC/MS at retention times of 1-11 min, the SHALO clusters were classified by CA using Origin 9.0 software. The average distance between groups, data standardization, and the Pearson correlation coefficient was chosen for hierarchical CA. As shown in Figure 12, the system CA tree diagram showed that seven types of oils could be classified, as follows: $S_{180}, S_{200}, S_{230}$, and $S_{250}$ belonging to cluster I, $S_{270}$ and $S_{300}$ belonging to cluster II, and $S_{\mathrm{rt}}$ belonging to cluster III. The classifications of clusters I and II were consistent with the inflection points of the $\mathrm{M}_{\mathrm{n}}, \mathrm{M}_{\mathrm{w}}, v_{40}, \mathrm{PP}$, and $\mathrm{AN}$ values of the oil samples at $250{ }^{\circ} \mathrm{C}$. The classification of $\mathrm{S}_{\mathrm{rt}}$ into cluster III was also consistent with the physical system studied. CA results at the molecular level were observed to be in good agreement with the changes observed to the physicochemical properties of the samples on the macro level. Gong et al. observed that hierarchical CA results based on two-channel and differential dielectric spectroscopy (TD-DES) data were also in good agreement with those based on FT-IR data and proposed using the TD-DES technique to monitor the oil and conduct hierarchical CA [54]. Furthermore, the present study offered a platform for further researching the molecular mechanism of oil sample degradation performance.

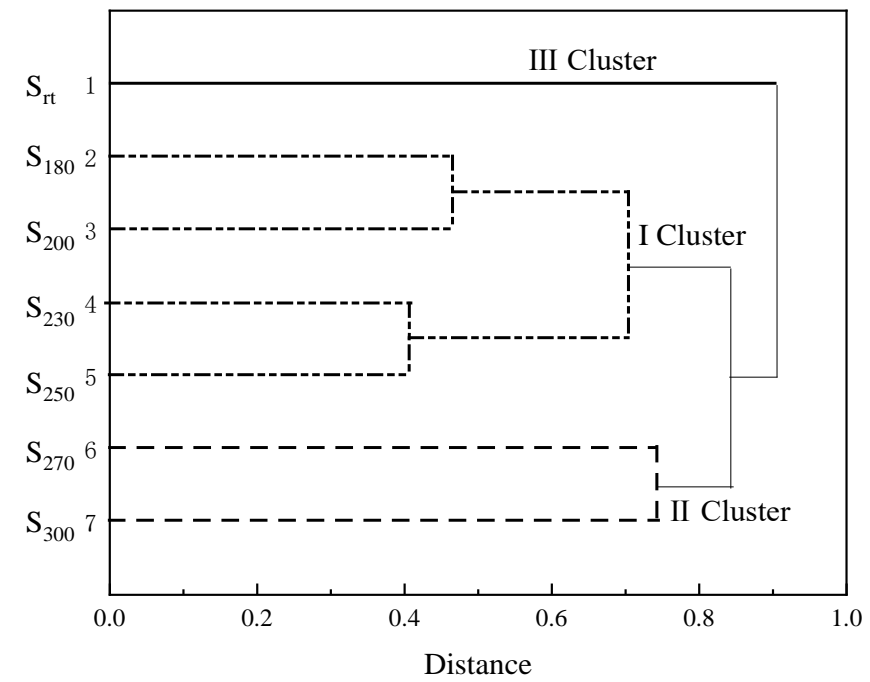

Figure 12. Dendrogram of the oil samples by cluster analysis based on the average linkage and Pearson correlation coefficients.

\section{Conclusions}

In this study, the compositional and structural characteristics of a SHALO were clarified under treatment at different temperatures through compound identification and analysis. The data provided scientific validation and technical support for molecular mechanisms related to the physicochemical properties and degree of SHALO deterioration as a function of temperature. Twenty functional groups, including comb-like alkanes, long-chain diesters, amines, and phenols, were identified in the SHALO. The antioxidants induced obvious effects that hindered the formation of free radicals, and NPAN was exhausted when the temperature was higher than $180^{\circ} \mathrm{C}$. Therefore, the cracking reactions were slower compared with polycondensation at low and medium temperatures $\left(<250{ }^{\circ} \mathrm{C}\right)$. However, at high temperatures $\left(>250^{\circ} \mathrm{C}\right)$, the role of the antioxidants gradually weakened, which significantly promoted the cracking reactions. The number and relative contents of small-molecule compounds in $S_{300}$, mainly composed of NAs, IPs, OFs, and AHs, were 52 and 4.600\%, which were significantly higher compared with those in $\mathrm{S}_{180}$ (15 and $2.228 \%$ ). A correlation existed between the rapid degradation of physicochemical properties (such as color, KV, PP, and AN) and the rapid increase in small-molecule compounds under high-temperature treatment. CA, based on the RCs of compounds, was in good 
agreement with the classification based on macroscopic physicochemical properties, which revealed the molecular mechanism of the degradation in properties at high TT temperatures. Furthermore, on this basis, the high-temperature SHALO performance would be improved, and the service life prolonged by developing chemical analysis.

Author Contributions: Writing of the article, Z.G. and T.Y.; experimental design, T.Y. and J.H.; material resource, X.L. and Y.S.; experimental work, T.Y. and M.Z.; data analysis, T.Y. and Z.G.; article review and editing, T.Y. All authors have read and agreed to the published version of the manuscript.

Funding: This research was funded by the Anhui Provincial Natural Science Foundation of China (Grant 1908085ME162), the Jiangsu Provincial Natural Science Foundation of China (BK20191155), the Open Research Project of Anhui Simulation Design and Modern Manufacture Engineering Technology Research Center (Huangshan University) (SGCZXZD1902), and the Scientific Research Projects Supported by Enterprises (hxkt20180043).

Conflicts of Interest: The authors declare no conflicts of interest.

\section{References}

1. Nagendramma, P.; Kaul, S. Development of ecofriendly/biodegradable lubricants: An overview. Renew. Sustain. Energy Rev. 2012, 16, 764-774. [CrossRef]

2. Raof, N.A.; Yunus, R.; Rashid, U.; Azis, N.; Yaakub, Z. Effect of molecular structure on oxidative degradation of ester based transformer oil. Tribol. Int. 2019, 140, 105852. [CrossRef]

3. Lansdown, A.R.; Lee, S. Aviation Lubricants. In Chemistry and Technology of Lubricants, 3rd ed.; Mortier, R.M., Fox, M.F., Orszulik, S.T., Eds.; Springer: Berlin/Heidelberg, Germany, 2010; pp. 345-351.

4. Matkovskiy, P.E.; Startseva, G.P.; Churkina, V.Y.; Knerel'Man, E.I.; Davydova, G.I.; Vasil'Eva, L.P.; Yarullin, R.S. Oligomerization of 1-decene under the action of catalytic systems based on Al-aluminum activator- $\mathrm{RCl}$ and Al-RCl. Polym. Sci. Ser. A 2008, 50, 1175-1186. [CrossRef]

5. Nagendramma, P.; Kaul, S.; Bisht, R.P.S. Study of synthesised ecofriendly and biodegradable esters: fire resistance and lubricating properties. Lubr. Sci. 2010, 22, 103-110. [CrossRef]

6. Kramer, D.C.; Ziemer, J.N.; Cheng, M.T.; Fry, C.E.; Reynolds, R.N.; Lok, B.K.; Sztenderowicz, M.L.; Krug, R.R. Influence of Group II \& III Base Oil Composition on VI and Oxidation Stability. Paper Presented at the 1999 AIChE Spring National Meeting, Houston; Chevron Products Company: Richmond, CA, USA, 1999.

7. Wu, N. Study on Structure-Activity Relationship of Thermal Oxidation Degradation of Poly $\alpha$-Olefin Aviation Lubricating Oil. Ph.D. Thesis, China University of Mining and Technology, Xuzhou, China, 2018.

8. Ye, Z.H. Research on Dynamic Behavior of High-Speed Rolling Bearings in Aero-Engines. Ph.D. Thesis, Harbin Institute of Technology, Harbin, China, 2013.

9. Jin, Y.; Duan, H.; Wei, L.; Cheng, B.; Chen, S.; Zhan, S.; Li, J. Comparison of the oxidation resistance of synthetic ester oils DOA and TDTM: Experimental evaluation and theoretical calculation. Lubr. Sci. 2019, 31, 252-261. [CrossRef]

10. Li, Z.; Lu, Y.; Zhang, C.; Dong, J.; Zhao, X.; Wang, L. Traction behaviours of aviation lubricating oil and the effects on the dynamic and thermal characteristics of high-speed ball bearings. Ind. Lubr. Tribol. 2019, 72, 15-23. [CrossRef]

11. Offunne, G.; Maduako, A.; Ojinnaka, C. Studies on the ageing characteristics of automotive crankcase oils. Tribol. Int. 1989, 22, 401-404. [CrossRef]

12. Zhang, X.; Murrenhoff, H.; Weckes, P.; Hölderich, W. Effect of temperature on the ageing behaviour of unsaturated ester-based lubricants. J. Synth. Lubr. 2004, 21, 1-11. [CrossRef]

13. Qian, X.; Xiang, Y.; Shang, H.; Cheng, B.; Zhan, S.; Li, J. Thermal-oxidation mechanism of dioctyl adipate base oil. Friction 2016, 4, 29-38. [CrossRef]

14. Yao, T.; Yang, H.W.; Fei, Y.W.; Guo, F.; Guo, L.; Bian, S. Performance-deterioration mechanism of lubricating based oil with metal catalysis. Petrkchem. Technol. 2017, 46, 1294-1303. [CrossRef]

15. Wu, Y.; Li, W.; Zhang, M.; Wang, X. Oxidative degradation of synthetic ester and its influence on tribological behavior. Tribol. Int. 2013, 64, 16-23. [CrossRef]

16. Vengudusamy, B.; Enekes, C.; Spallek, R. EHD friction properties of ISO VG 320 gear oils with smooth and rough surfaces. Friction 2019, 8, 164-181. [CrossRef] 
17. Novikov, A.S.; Yanovskii, L.S.; Ezhov, V.M.; Molokanov, A.; Sharanina, K.V. Effect of Lubricating-Oil Foamability on Oil-System Operation in Aviation Gas-Turbine Engines. Chem. Technol. Fuels Oils 2017, 53, 15-22. [CrossRef]

18. Sheng, H.; Xinguo, C.; Shujie, M.; Tianhui, R. The mechanism of thermal oxidation of a hydrotreated naphthenic lube base oil at high temperature. Chem. Technol. Fuels Oils 2009, 45, 260-266. [CrossRef]

19. Vijh, A.K. Electrochemically based approaches to the preservation of lubricating oils under high temperature friction conditions. Wear 1986, 107, 287-288. [CrossRef]

20. Moustafa, N.E.; Eissa, E.A. Inverse gas chromatographic study of the oxidation stability of lubricating base oils via solubility parameter calculations. Chin. J. Chromatogr. 2007, 25, 871-875. [CrossRef]

21. Jain, M.R.; Sawant, R.; Paulmer, R.; Ganguli, D.; Vasudev, G. Evaluation of thermo-oxidative characteristics of gear oils by different techniques: Effect of antioxidant chemistry. Thermochim. Acta 2005, 435, 172-175. [CrossRef]

22. Egharevba, F.; Maduako, A.U.C. Assessment of Oxidation in Automotive Crankcase Lube Oil: Effects of Metal and Water Activity. Ind. Eng. Chem. Res. 2002, 41, 3473-3481. [CrossRef]

23. Qiao, X.J.; Tian, H.X. Application of system clustering method and principle component analysis method in clustering analysis of lubricating oil. Lubr. Eng. 2013, 38, 99-103. [CrossRef]

24. Uy, D.; Simko, S.J.; Carter, R.; Jensen, R.K.; Gangopadhyay, A.K. Characterization of anti-wear films formed from fresh and aged engine oils. Wear 2007, 263, 1165-1174. [CrossRef]

25. Mascolo, G.; Rausa, R.; Bagnuolo, G.; Mininni, G.; Tinucci, L. Thermal degradation of synthetic lubricants under oxidative pyrolytic conditions. J. Anal. Appl. Pyrolysis 2006, 75, 167-173. [CrossRef]

26. Tripathi, A.K.; Vinu, R. Characterization of Thermal Stability of Synthetic and Semi-Synthetic Engine Oils. Lubricants 2015, 3, 54-79. [CrossRef]

27. Keller, M.A.; Saba, C.S. Gas Chromatographic Monitoring of Hydroxyl Components in Oxidized Turbine Engine Lubricants. Tribol. Trans. 2003, 46, 576-579. [CrossRef]

28. Levermore, D.M.; Josowicz, M.; Rees, W.S.; Janata, J. Headspace analysis of engine oil by gas chromatography/mass spectrometry. Anal. Chem. 2001, 73, 1361-1365. [CrossRef]

29. Santos, J.C.O.; Dos Santos, I.M.G.; Souza, A.G.; Sobrinho, E.V.; Fernandes, V.J., Jr.; Silva, A.J.N. Thermoanalytical and rheological characterization of automotive mineral lubricants after thermal degradation. Fuel 2004, 83, 2393-2399. [CrossRef]

30. Goyenola, C.; Stafström, S.; Schmidt, S.; Hultman, L.; Gueorguiev, G. Carbon Fluoride, CFx: Structural Diversity as Predicted by First Principles. J. Phys. Chem. C 2014, 118, 6514-6521. [CrossRef]

31. Dos Santos, R.B.; Rivelino, R.; Mota, F.D.B.; Kakanakova-Georgieva, A.; Gueorguiev, G. Feasibility of novel $\left(\mathrm{H}_{3} \mathrm{C}\right)_{n} \mathrm{X}\left(\mathrm{SiH}_{3}\right)_{3-\mathrm{n}}$ compounds $(\mathrm{X}=\mathrm{B}, \mathrm{Al}, \mathrm{Ga}, \mathrm{In})$ : structure, stability, reactivity, and Raman characterization from ab initio calculations. Dalton Trans. 2015, 44, 3356-3366. [CrossRef]

32. Petroleum Products - Determination of Color; GB/T6540-1986; Research Institute of Petroleum Processing: Beijing, China, 1987.

33. Petroleum Products - Determination of Kinematic Viscosity and Calculation of Dynamic Viscosity; GB/T 265/1988; Takahashi Petrochemical Company: Shanghai, China, 1989.

34. Petroleum Products and Lubricants - Determination of Acid Number - Potentiometric Titration Method; GB/T7304-2000; Lanzhou Petrochemical Complex: Lanzhou, China, 2001.

35. Petroleum Products - Determination of Pour Point; GB/T3535-2006; Research Institute of Petroleum Processing: Beijing, China, 2006.

36. Qi, Y.P.; Li, T.L.; Guo, G.G. The production and application of $\alpha$-olefin. Petrochem. Ind. Tech. 2008, 15, 53-56, 73. [CrossRef]

37. Colyer, C.C.; Gergel, W.C. Chemistry and Technology of Lubricants. In Chemistry and Technology of Lubricants, 2nd ed.; Mortire, R.M., Orszulik, S.T., Eds.; Springer: Berlin/Heidelberg, Germany, 1997; pp. 72-73.

38. Zhao, L.; Liu, X.D. Study on the features of lubricants for alternative refrigerants and on the mechanism of additives. J. Xi'an Univ. Arch. Tech. 2002, 34, 252-255. [CrossRef]

39. Okoye, I.P.; Khama, A.G.; Akaranta, O. The effect of natural antioxidants (from groundnut shell extracts) on the oxidation stability of lubricating oil. Glob. J. Pure App. Sci. 2010, 16, 423-427.

40. Adhvaryu, A.; Perez, J.M.; Duda, L.J. Quantitative NMR Spectroscopy for the Prediction of Base Oil Properties. Tribol. Trans. 2000, 43, 245-250. [CrossRef] 
41. Xin, M.L.; Li, M.D.; Yang, B.; Zhang, S.K.; Huang, G.J. Antioxidant mechanism and development trend of antioxidants in polymers. Plast. Sci. Tech. 2017, 45, 100-106. [CrossRef]

42. Yao, T.; Hao, J.T.; Guo, L.; Xiao, Y.P.; Jiang, H.Z.; Guo, Q.P.; Fei, Y.W. The relationship between structure and property about poly $\alpha$-olefin aviation lubricaiting base oil at high temperature condition. Lubr. Eng. 2016, 41, 91-106. [CrossRef]

43. Ghosh, P.; Hoque, M.; Karmakar, G.; Das, M.K. Dodecyl methacrylate and vinyl acetate copolymers as viscosity modifier and pour point depressant for lubricating oil. Int. J. Ind. Chem. 2017, 8, 197-205. [CrossRef]

44. Neary, V.S.; Odgaard, A.J. Closure to "Three-Dimensional Flow Structure at Open-Channel Diversions" by Vincent S. Neary and A. Jacob Odgaard. J. Hydraul. Eng. 1995, 121, 88-90. [CrossRef]

45. Siouris, S.; Wilson, C.W. Thermodynamic Properties of Pentaerythritol-Based Species Involved in Degradation of Aviation Gas Turbine Lubricants. Ind. Eng. Chem. Res. 2010, 49, 12294-12301. [CrossRef]

46. Kreivaitis, R.; Padgurskas, J.; Gumbyte, M.; Makareviciene, V.; Spruogis, B. The influence of oxidation on tribological properties of rapeseed oil. Transport 2011, 26, 121-127. [CrossRef]

47. Mousavi, P.; Wang, D.; Grant, C.S.; Oxenham, W.; Hauser, P.J. Effects of Antioxidants on the Thermal Degradation of a Polyol Ester Lubricant Using GPC. Ind. Eng. Chem. Res. 2006, 45, 15-22. [CrossRef]

48. Khelfaoui, M.; Sedkaoui, S. Sharing Economy and Big Data Analytics, 1st ed.; John Wiley and Sons: Hoboken, NJ, USA, 2020; pp. 195-214.

49. Yang, S.; Berdine, G. Cluster analysis. Southwest Respir. Crit. Care Chronicles 2018, 6, 37-40. [CrossRef]

50. Wakiru, J.; Pintelon, L.; Chemweno, P.; Muchiri, P. Analysis of lubrication oil contamination by fuel dilution with application of cluster analysis. In Proceedings of the XVII International Scientific Conference on Industrial Systems (IS'17), University of Novi Sad, Novi Sad, Serbia, 4-6 October 2017.

51. Wakiru, J.M.; Pintelon, L.; Muchiri, P.N.; Chemweno, P. A review on lubricant condition monitoring information analysis for maintenance decision support. Mech. Syst. Signal Process. 2019, 118, 108-132. [CrossRef]

52. Ragno, G.; De Luca, M.; Ioele, G. An application of cluster analysis and multivariate classification methods to spring water monitoring data. Microchem. J. 2007, 87, 119-127. [CrossRef]

53. Zięba-Palus, J.; Kościelniak, P.; Łaccki, M. Differentiation of used motor oils on the basis of their IR spectra with application of cluster analysis. J. Mol. Struct. 2001, 596, 221-228. [CrossRef]

54. Gong, Y.; Guan, L.; Feng, X.; Wang, L.; Yu, X. In-situ lubricating oil condition sensoring method based on two-channel and differential dielectric spectroscopy combined with supervised hierarchical clustering analysis. Chemom. Intell. Lab. Syst. 2016, 158, 155-164. [CrossRef] 